\title{
Material Stock Demographics: Cars in Great Britain
}

\author{
André Cabrera Serrenho* and Julian M. Allwood \\ Department of Engineering, University of Cambridge, Trumpington Street, Cambridge CB2 1PZ, United Kingdom
}

\section{Supporting Information}

ABSTRACT: Recent literature on material flow analysis has been focused on quantitative characterization of past material flows. Fewer analyses exist on past and prospective quantification of stocks of materials in-use. Some of these analyses explore the composition of products' stocks, but a focus on the characterization of material stocks and its relation with service delivery is often neglected. We propose the use of the methods of human demography to characterize material stocks, defined herein as stock demographics, exploring the insights that this approach could provide for the sustainable management of materials. We exemplify an application of stock demographics by characterizing the composition and service delivery of iron, steel, and aluminum stocks of cars in Great Britain, 2002-2012. The results show that in this period the stock has become heavier, it is traveling less, and it is idle for more time. The visualization of material stocks' dynamics demonstrates the pace of product replacement as a function of its usefulness and enables the formulation of policy interventions and the exploration of future trends.

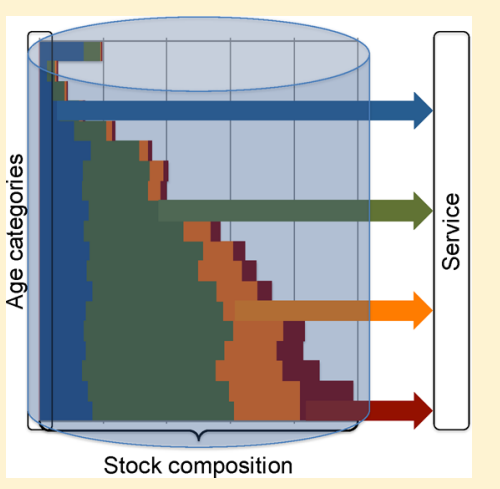

\section{INTRODUCTION}

Many human activities depend on services provided by stocks of materials in the form of products: ${ }^{1}$ transportation requires vehicles, shelter is provided by buildings, and production is enabled by machines. These stocks result from the accumulation of material over time, and this production drives key environmental impacts. ${ }^{2}$ Global physical constraints require the promotion of resource efficiency and the minimization of greenhouse gas emissions. ${ }^{1-3}$ Pursuing these objectives could be facilitated by enhanced knowledge on the composition of material stocks and their relation to service delivery.

Material flow analysis has been used extensively to characterize the transformation of materials along supply chains. Most material flow analyses are static, describing a system for a particular time period, usually one year, and have been used for various purposes: (i) identifying opportunities for efficiency improvements; ${ }^{2}$ (ii) assessing risks, either by evaluating the degree of environmental exposure across the supply chain ${ }^{4}$ or by anticipating the consequences of a demand or supply shock; 5 (iii) obtaining aggregate indicators on changes to the physical structure of socioeconomic systems. ${ }^{6,7}$ In contrast to life cycle analyses, which are focused on products, material flow analyses examine flows from raw materials through end-use products to end-of-life scrap.

Few analyses account for stocks of materials. Chen and Graedel $^{8}$ and Müller et al. ${ }^{9}$ summarize the two main approaches used to estimate stocks: (i) a top-down approach that uses information on material flows over a significant time period; (ii) a bottom-up approach that uses information on the number of physical units by product and their material composition. Bottom-up approaches enable a static analysis, such as Tanikawa et al. ${ }^{10}$ who predict construction stocks in Japan from inventories of physical units and estimate their material composition, allowing Fishman et al. ${ }^{11}$ to identify the socioeconomic drivers of material accumulation. Wang et al. ${ }^{12}$ have also used a bottom-up approach to quantify iron and steel stocks by product categories for China in 2000 and 2010. Topdown approaches allow dynamic analyses that account for past material accumulations and examine trends. This information is often used for prediction.

Dynamic approaches have been used by Müller et al. ${ }^{13}$ who consider the relationship between service delivery and stocks and flows of wood in Switzerland by modeling the cohort composition of each stock over time. Müller ${ }^{14}$ has also used this method to examine past trends and to forecast future cement flows for housing in The Netherlands. The modeling approaches used by these two analyses have also been used for other products, materials, and metrics of service delivery. Sandberg and Bratteb $\emptyset^{15}$ and Sandberg et al. ${ }^{16}$ anticipate future buildings stocks in Norway and predict the energy and material flows required to deliver them. $\mathrm{Hu}$ et al. ${ }^{17}$ examine steel in Chinese residential buildings from 1900 to 2100, considering the floor area as a service metric. More recently, Sandberg and Bratteb $\varnothing^{15}$ have updated this metric to heated floor area, estimating the use-phase energy requirements of the building stock. For infrastructure, Busch et al. ${ }^{18}$ model the composition of stocks of critical materials over time. For several products, Pauliuk et al. ${ }^{19}$ have provided estimates on Chinese steel demand and scrap availability over the 21 st century, distinguishing between four product categories (construction, transportation, machinery, appliances, and other) and assuming average lifetimes for each category.

Received: October 12, 2015

Revised: February 12, 2016

Accepted: February 12, 2016

Published: February 12, 2016 


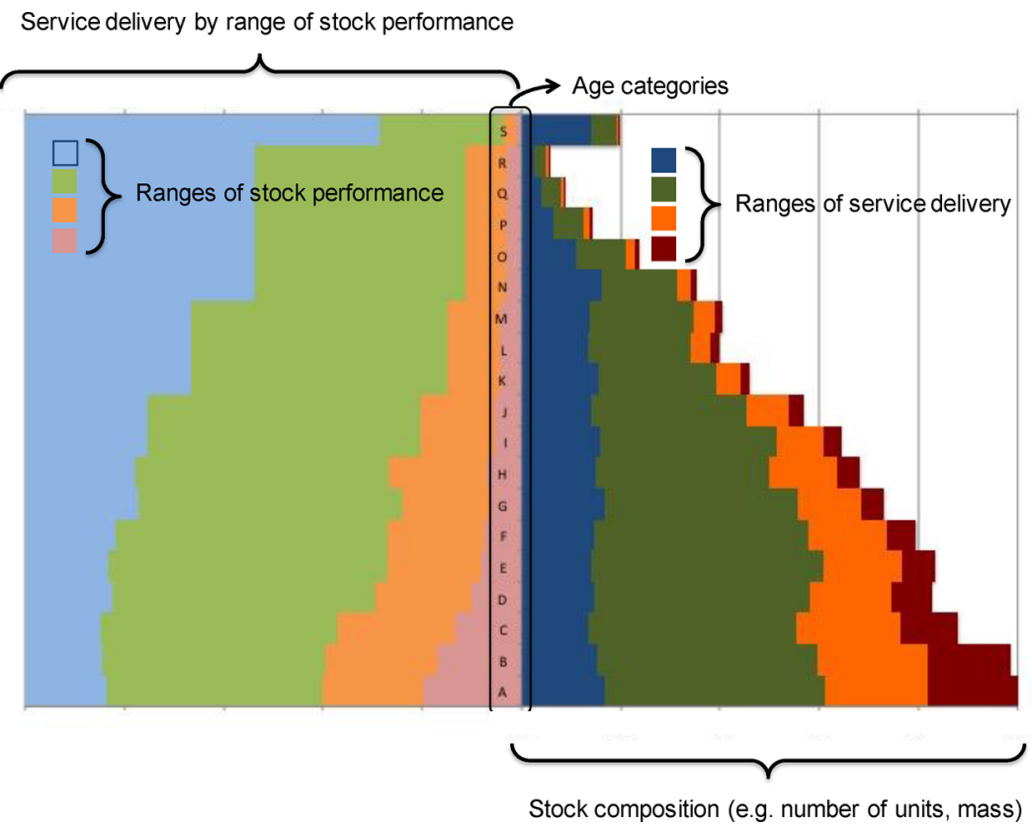

Figure 1. Representation of stock composition by age and ranges of service performance.

Müller's modeling approaches ${ }^{13,14}$ have also been used to examine stocks of vehicles. Modaresi et al. ${ }^{20}$ consider the global fleet of passenger cars, examining scenarios with different material compositions and vehicle weights and predicting their impacts on recycling; Løvik et al. ${ }^{21}$ characterize the composition of different aluminum alloys. Oguchi and Fuse ${ }^{22}$ estimate the distribution of cars' lifespan for 17 countries, highlighting the need to model products' lifetime accurately. Recently, Pauliuk and Müller ${ }^{1}$ recognized the role of stocks in providing services and demonstrated that decoupling service from stock and stock from throughput has a substantial emissions savings potential. Using the Chinese passenger car fleet as a case study, Pauliuk and Müller ${ }^{1}$ have examined the effect of changing consumer behavior (by changing the demand for services provided by the car fleet) in future flows and stocks of steel. Existing vehicle fleet models are capable of modeling effects on air quality and transportation planning, by considering the composition of stock, service delivery, and vehicle emissions at different geographical scales. ${ }^{23,24}$

The analyses above provide compelling insights into past and prospective product and material flows and stocks, and their environmental impacts. This has also been the case for some integrated assessment models, which have been used extensively for policy analysis, although these models often do not comply with the principles of mass balance and they have not been focused on material composition of stocks. ${ }^{25}$ Most existing dynamic material flow analyses model the cohort composition of stocks over time, and some of them explore the relationship between stocks and service delivery. ${ }^{14}$ However, a representation of material stocks' performance, exploring the patterns of use of stocks, has barely been explored. Such a representation may give insights about the pace of product replacement as a function of its usefulness and hence enable the formulation of policy interventions aimed at minimizing the demand for new material production.

Human demography is a long-established science that studies the composition of populations, their age distribution, dynamics, wealth, and productivity. Demography has been used for decision-making by public and private sectors, addressing problems as diverse as the identification of health risk, the sustainability of welfare systems, urban planning, or even market analysis. ${ }^{26-29}$ The objectives of human demography are similar to the characterization of material stocks, despite their different contexts. To explore this similarity, in this paper we employ the methods of human demography for material stocks and define this as stock demographics. We explore a representation of material stocks' composition and examine their implications for service delivery over time. We start with a brief review of the main applications of human demography and ask how demographic methods could be used to characterize material stocks (section 2). Data on passenger cars in Great Britain and the service they provide allow us to demonstrate the use of stock demographics for cars (section 3 ). These results and their implications are discussed in section 4 .

\section{EMPLOYING HUMAN DEMOGRAPHY FOR MATERIAL POPULATIONS}

In this section we review the main applications of human demography (section 2.1), discuss the metrics used to characterize stocks and their services (section 2.2), and examine how demography can be used to characterize material stocks (section 2.3). This is demonstrated by assessing the stock of cars in Great Britain. The required methods and data sources are described in section 2.4 and results presented in section 3 .

2.1. Applications of Human Demography. Human demography is the study of the structure and composition of human populations. Swanson et al. ${ }^{27}$ define applied demography as a science oriented for decision-making that can inform specific policy questions. The uses of applied demography have been diverse, originally focused on the sustainability of social security schemes and now spanning from the planning of urban and transport developments to the analysis of market segmentation or employees' turnover. ${ }^{28}$ Murdock and Swanson $^{29}$ describe the use of demography to solve problems of human health. As human populations become more diverse and grow older, the assessment of the demographic characteristics that increase exposure to health risks allows identification of adequate responses. 
Table 1. Examples of Stock Demographics' Pyramids, Using the Representation of Figure $1^{a}$

\begin{tabular}{l}
\hline Pyramid type \\
\hline $\begin{array}{l}\text { Service delivery changes significantly with product age (left-hand side). An } \\
\text { expansive pyramid suggests that new additions to stock contribute to } \\
\text { increase the overall stock performance, since the stock performance of the } \\
\text { younger cohorts is higher than the average performance of the existing } \\
\text { stock. }\end{array}$ \\
\hline $\begin{array}{l}\text { Service delivery changes significantly with product age (left-hand side). A } \\
\text { constrictive pyramid suggests that a reduction in new additions to stock } \\
\text { contribute to reduce the overall stock performance, since the stock } \\
\text { performance of the younger cohorts is higher than the average } \\
\text { performance of the existing stock. }\end{array}$ \\
\hline
\end{tabular}

Service delivery does not change significantly with product age, since it is not visible a clear loss of service performance with age (left-hand side). Stock dynamics does not affect the overall stock performance.

${ }^{a}$ Red, orange, green, and blue represent very high, high, low, and very low levels of stock performance, respectively.

Keyfitz $^{26}$ identifies age as the main characteristic variable of population analyses and concludes that demography is much concerned with examining the effects of age distribution. Besides age, demography applications often involve the estimation of more complex characteristics such as birthplace, ethnicity, level of education, or income. Applied demography analyses entail the study of how these characteristics are related for a population or a particular cohort.

Could we employ the methods that human demography uses to assess populations for characterizing in-use material stocks? In the next section we explore the metrics used to characterize material stocks the service they deliver, and in section 2.3 we evaluate the merits of this proposal.

2.2. Characterizing Material Stocks. Like human populations, stocks comprise individual components (such as products), each providing some level of service. There is thus heterogeneity in stock composition and performance that reflects the diversity of use patterns and age of individual products. These are essential variables to assess stock dynamics, because they characterize the pace of product replacement as a function of usefulness. New product purchasing, imports and exports, vintage, and end-of-life have their demography counterparts as birth, migration, aging, and death, respectively. So, how could we use demography's approaches to characterize stock composition and service delivery?

Stock demographics should characterize individual stock components by their age. Graphical representation, similar to demographic pyramids, allows characterization of changes in the age of each cohort over time (right-hand side of Figure 1).

Material stocks are usually measured in units of mass. However, the ontological dissimilarity between accumulated mass and their uses prevents the use of the same units to measure stocks and the services they provide. Besides, different services require different units. Thus, stock and service metrics can only be coupled by intensity measures, such as the ratio of service delivery to stock, which has previously been named inconsistently in the literature and defined henceforth as stock performance:

$$
\text { stock performance }=\frac{\text { service delivery }}{\text { stock }}
$$

Service delivery can be represented on a stock composition pyramid by adding different colors for ranges of service delivery, as shown in Figure 1. The left-hand side of the proposed representation characterizes service delivery for each cohort broken down into different ranges of stock performance.

2.3. Using Stock Demographics for Sustainable Management of Materials. Stock demographics enables the characterization of stocks' composition, their performance, and age. However, how can this approach provide useful insights for mitigating environmental harm in the management of material flows and stocks?

Environmental impacts are generated during the use, production, and end-of-life phases of a product's life. Enhanced knowledge of how stocks provide services to their users and how this evolves over time allows a better understanding of stocks' dynamics and may be able to estimate future material flows and their impacts.

Thompson and Lewis ${ }^{30}$ distinguish three main types of human population pyramids: expansive, for young and growing populations; constrictive, for populations with decreasing reproduction rates; stationary, for populations with cohorts of similar sizes. These pyramids reveal different population dynamics, whose interpretation can be applied to characterize stocks. A simultaneous representation of the size (pyramid in the right-hand side of Figure 1), service delivery (colors in the right-hand side of Figure 1), and a breakdown by ranges of stock performance (left-hand side of Figure 1) for each cohort enable the characterization of the impact of product age on service delivery. Table 1 exemplifies the insights given by some typical examples of stock demographics' pyramids.

2.4. Stock Demographics of Cars in Great Britain. The availability of data on the car fleet in Great Britain allows us to exemplify the use of stock demographics. This is achieved by compiling data on stock composition (section 2.4.1) and service delivery (section 2.4.2).

2.4.1. Characterizing Stock Composition. The size and composition of the stock of cars was obtained from the vehicle licensing statistics ${ }^{31}$ that provide the number of licensed cars in Great Britain by year of first registration (details can be found in the Supporting Information file). Data on the material composition of cars is scarce and mainly available for new models for the USA. $\mathrm{CAR}^{32}$ and Keoleian and Sullivan ${ }^{33}$ 

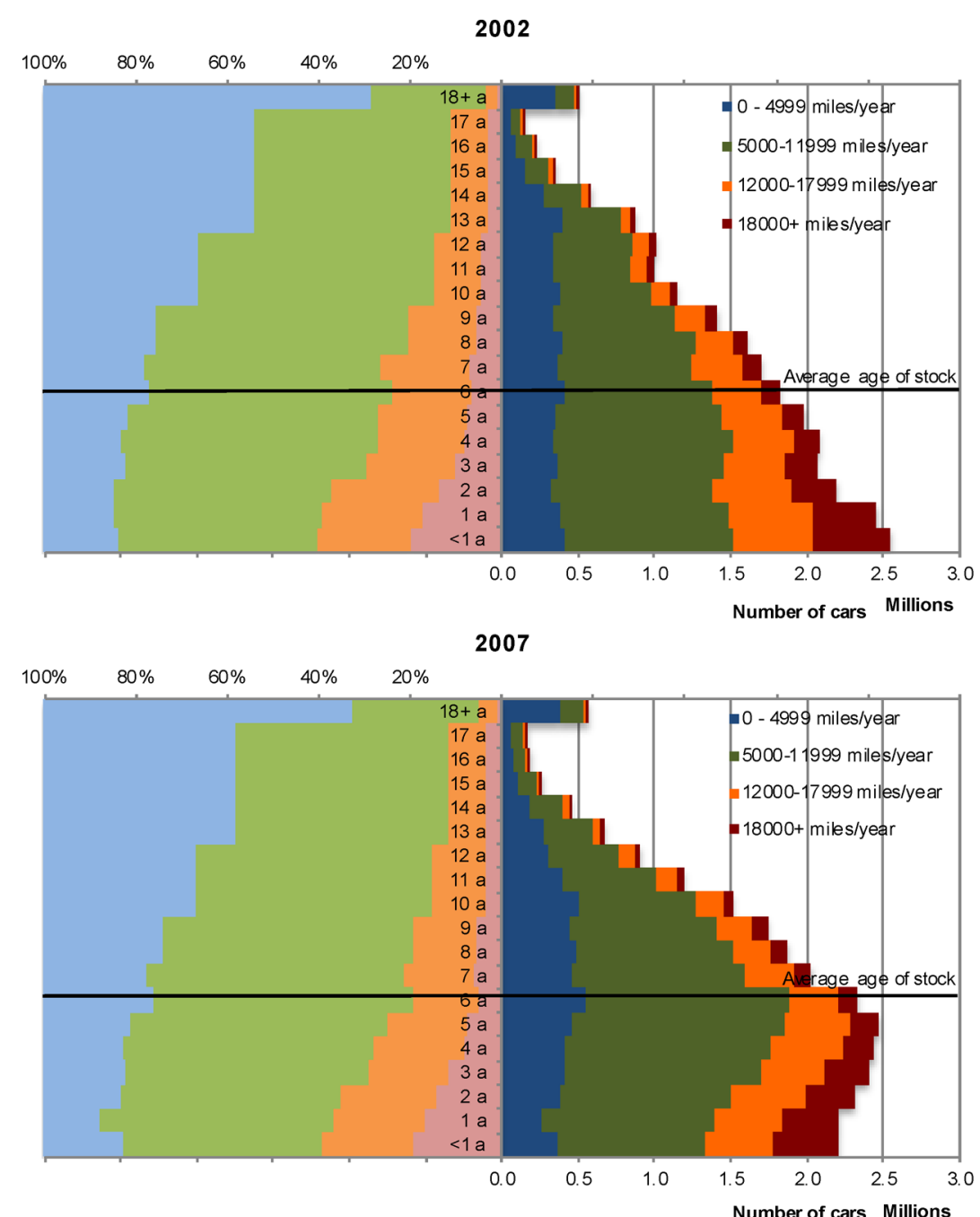

2012

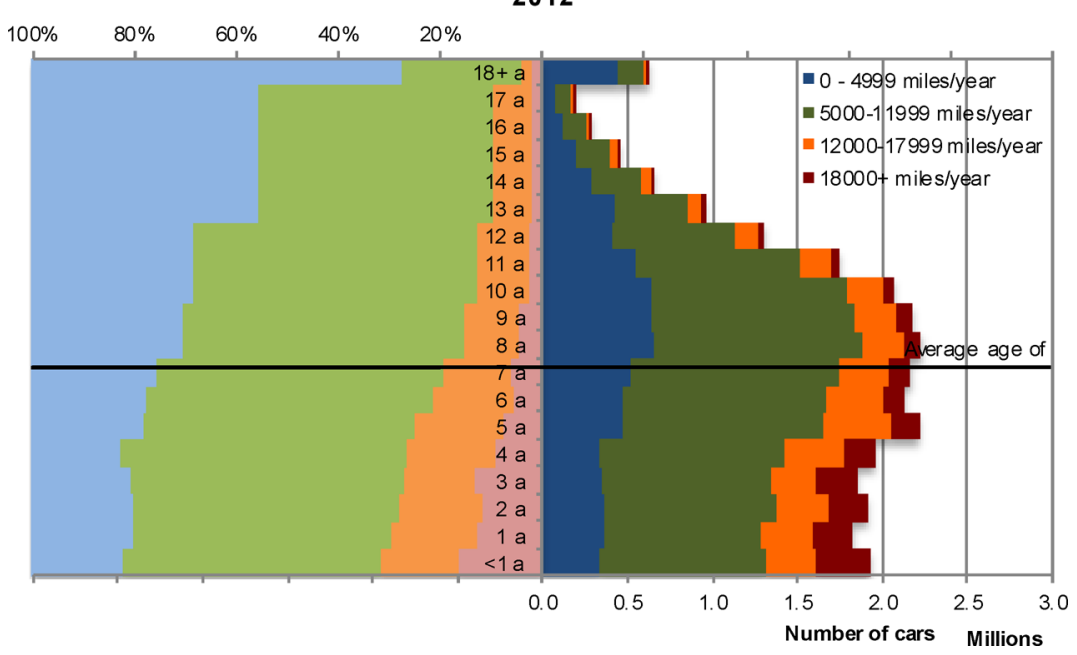

Figure 2. Stock demographics of cars in Great Britain in 2002, 2007, and 2012.

present data on the average material composition of USA cars for new models registered in 1985, 1990, 1995, 2000, and 2009. Despite significant differences in average curb weight and engine capacity for American cars, the global automotive market results in similar safety standards and accessories worldwide for each year. For this reason, the material composition shares of USA cars were used as a proxy for the
British average. This approach has also been used by Modaresi et al., ${ }^{20}$ who have identified iron, steel, and aluminum as the materials that drive most of curb mass and whose production is associated with the highest production greenhouse gases emissions.

The International Council on Clean Transportation Europe publishes annually average statistics on new cars registered in 

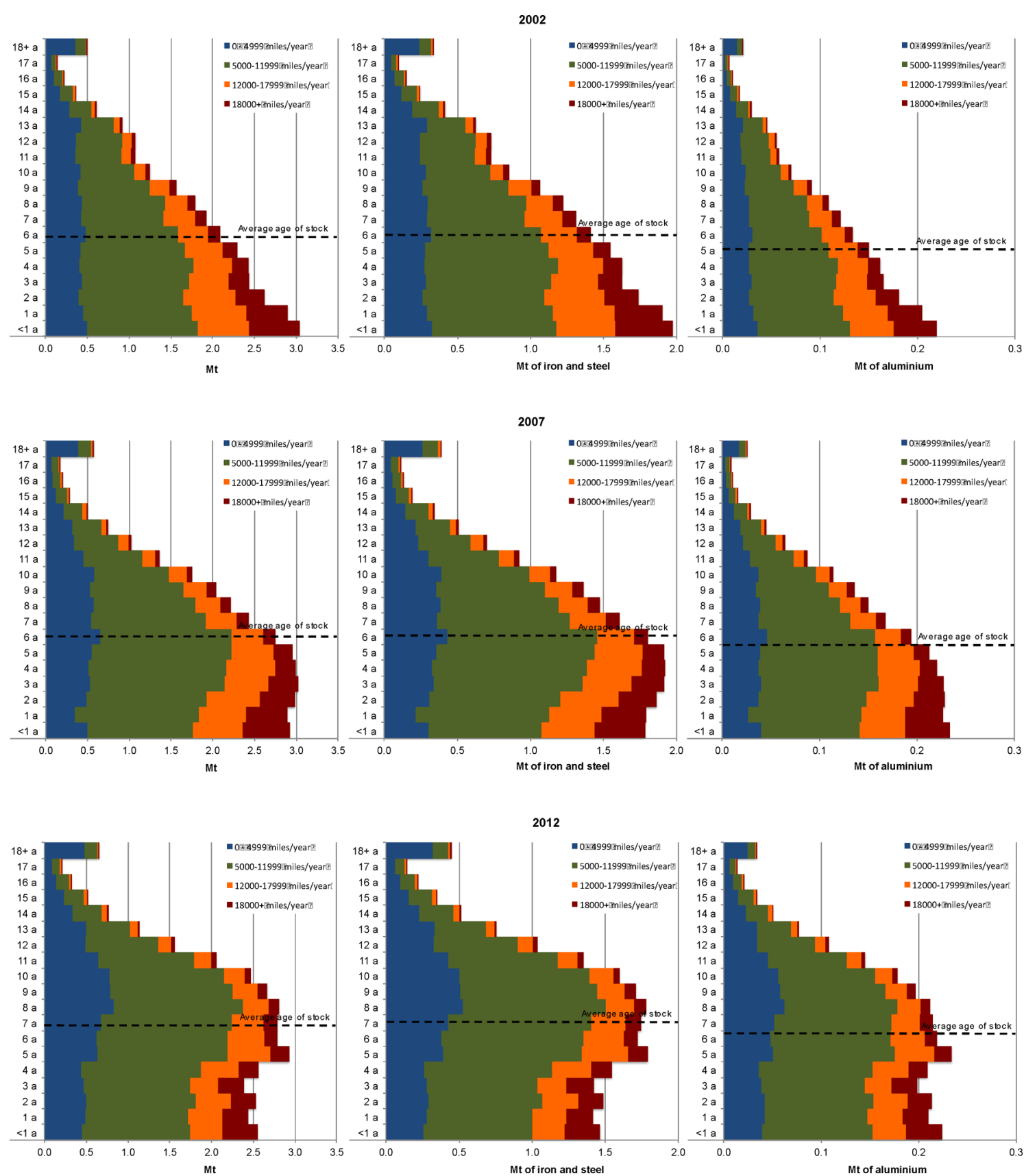

Figure 3. Car stock composition and miles driven by curb weight, mass of iron and steel components, and mass of aluminum for Great Britain in 2002, 2007 and 2012.

each European Union country. ${ }^{34}$ In particular their statistics on the average mass of new cars allow us to estimate the average curb weight of the entire fleet from 2002 to 2012.

These references on material composition and weight of new vehicles have provided data for our estimate of the material composition of the car fleet. Average curb weight of new cars was obtained from ICCT $^{35}$ statistics for new cars in the UK from 2001 to 2012, subtracting $75 \mathrm{~kg}$ for the driver. Average material composition was obtained from $\mathrm{CAR}^{32}$ for 1985 and 1990, and from Keoleian and Sullivan ${ }^{33}$ for 1995, 2000, and 2009. Missing values were obtained by linear interpolation. Other interpolation methods could have been used, but the impact of a different method on results is likely to be small, because the changes between each of these intervals are smaller than $10 \%$. Average material composition was obtained using the curb weight and composition estimates for new cars described above and the characterization of stock composition by year of registration described previously. The full data set of material composition and curb weight estimates is presented in detail in the Supporting Information.

2.4.2. Accounting for Service Delivery. Existing analyses on transportation services use distance traveled ${ }^{36}$ or the product of vehicle occupancy and distance traveled ${ }^{37}$ as the main metrics of service delivery. These metrics have different foci: vehicle $\mathrm{km}$ is centered on product performance, whereas passenger $\mathrm{km}$ is centered on people's transportation. In this analysis, distance traveled per vehicle is used, although stock demographics can be employed regardless of the nature of stock or the service metric used. Service delivery by car and vehicle age were estimated from the National Travel Survey. ${ }^{38}$ 
Service characterization followed the framework proposed in section 2.3. This representation implies (i) the definition of car age categories, (ii) and the definition of ranges of stock performance. Only four levels of service have been defined to facilitate the readability of the resulting graphs: cars traveling less than $5000 \mathrm{mi} /$ year, between 5000 and $12000 \mathrm{mi} /$ year, between $12000 \mathrm{mi} /$ year and $18000 \mathrm{mi} /$ year, and $18000 \mathrm{mi} /$ year or more. Car age categories have been disaggregated as much as available data allowed, resulting in yearly categories up to the age of 17, beyond which older cars have been aggregated. Details on the calculation of distance traveled by car age category can be found in the Supporting Information. The characterization of cars described here enabled the visualization of stock demographics, which is presented in the next section.

\section{VISUALIZING THE DEMOGRAPHICS OF CARS IN GREAT BRITAIN}

The proposed representation of stock demographics can be shown in terms of the number of units or in terms of the curb mass and its individual materials. These are shown in the following two sections.

3.1. Stock Demographics: Number of Units. Figure 2 shows the service delivery and composition of cars in Great Britain for 2002, 2007, and 2012. Individual graphs for each year from 2002 to 2012 can be found in the Supporting Information.

Figure 2 illustrates the changes in the composition of the car fleet and service delivery over this period. The right-hand side of the diagram evolves from an expansive pyramid in 2002 to a constrictive pyramid in 2012, when the stock of cars was older and midage cars became the most common cohort. The lefthand side of the diagrams show the heterogeneity of service delivery, as a higher share of younger cars is used for high mileages. The distribution of stock performance for each cohort seems to be stable from 2002 to 2012, despite significant changes in the composition of stock. Given the above, stock aging resulted in a decrease in the overall stock performance, so that the average distance traveled per year per vehicle decreased from $14600 \mathrm{~km}$ in 2002 to $13300 \mathrm{~km}$ in 2012. In 2012 the stock of cars is bigger but is used less intensively.

3.2. Stock Demographics: Mass of Materials. Figure 3 shows the evolution of total curb weight and for the stock of iron, steel, and aluminum in 2002, 2007, and 2012. As an example, the breakdown of material cohort by annual miles driven is shown, although other features or service units could have been represented.

The results (described in detail in the Supporting Information) show that average curb weight of the fleet has increased from 2002 to 2012. The stock of iron and steel evolves from an expansive to a constrictive pyramid in 2007 and 2012, because there was a decrease in the mass of these materials in new cars. This is a joint consequence of a decrease in the number of new cars and a decrease in the share of iron and steel in the total weight of new cars, despite an increase in the curb weight. The stock of aluminum becomes older but exhibits a profile different from that of iron and steel. It evolves from an expansive pyramid in 2002 to stationary (rather than constrictive) pyramids in 2007 and 2012. This demonstrates that new aluminum was added to stock, as a joint consequence of an increase in curb weight and an increased aluminum content in new cars, despite a decrease in the number of new cars added to the stock.

\section{DISCUSSION}

The results presented in section 3 suggest that cars in Great Britain have more iron, steel, and aluminum and are heavier now than in the past. Current policies, such as the mandatory emissions reduction targets for new cars set by the European Union, ${ }^{39}$ are focused on reducing the use-phase emissions of cars. This policy requires a substantial reduction in the average emissions of the fleet by 2021 but fails to promote a reduction in the average weight of the fleet. Reducing the mass of the vehicle while providing the same service could simultaneously promote emissions reductions and energy and emissions savings upstream in material production.

Cars are traveling less and are idle for more time: more metal is delivering less transportation service, and its intensity of use is decreasing. On average, in 2002 each car traveled $14600 \mathrm{~km}$ and was used for only $6 \mathrm{~h}$ and $20 \mathrm{~min}$ per week. In 2012 the average distance was shortened to $13300 \mathrm{~km}$ and the intensity of use decreased to $5 \mathrm{~h}$ and $40 \mathrm{~min}$ per week. Currently, $15 \mathrm{Mt}$ of carbon dioxide emissions are produced globally to supply the UK annual demand for vehicles, ${ }^{40}$ so there is a potential for substantial emissions savings as a result of policies aimed at increasing the intensity of use of cars, while reducing the need for new vehicles. Such policies could include the following: higher tax on car ownership, increased parking charges, or incentivise shared ownership and autonomous driving.

Only a small fraction of cars is used for a high mileage. Existing stock performance could be enhanced, also contributing to reducing the demand for new vehicles and their manufacturing impacts. Policies aimed at promoting lifetime extension, such as encouraging repair and maintenance or increased scrappage charging, could simultaneously reduce the demand for new and potentially heavier cars and counteract the recent declining distance traveled by older cars. In 2012 most cars used for midrange mileage were aged 5 to 10 years, which suggests that consumer behavior may not be a significant barrier for the extension of this range of performance beyond this age, provided conditions for vehicles' lifetime extension are promoted.

Most cars have consistently been scrapped between 10 and 13 years old. Stock demographics shows us the recent trends in cars' lifetime, which are helpful to estimate the future supply of cars for scrap and recycling. Stock demographics also enables the assessment of the effects of policy interventions (such as the promotion of lifetime extension) on the demand for new material flows and the future availability of end-of-life materials. The evolution of iron and steel stocks (Figure 3) suggests an absolute loss in the future stock. Thus, significant amounts of iron and steel scrap are expected to become available over the next decade from end-of-life cars, provided vehicle lifetimes are maintained.

Gutowski et al. ${ }^{41}$ and Allwood et al. ${ }^{2}$ have confirmed that significant efforts to address material efficiency and material demand reduction are required to deliver global greenhouse gases emissions targets. Dynamic material flow analyses may benefit from highlighting the material stock-service relationship, informing the impact that changes in products' service delivery may have in their rate of replacement. Stock demographics provides a consistent framework for assessing the merits of different options aimed at reducing demand for new materials, by means of a visualization tool that represents the heterogeneity of material composition and service delivery, and reflects the diversity of patterns of use and age over time. 
Stock demographics can be developed beyond the example presented in this paper for assessing either other stocks of cars or stocks of other products, provided there are estimates of material composition, an inventory of its change over time, and the service provided. Compiling such data may be challenging, but refining stock demographics analyses may reveal new potentials. A more refined categorization of the stock of cars, e.g., by assessing more materials or by exploring the demographics at a brand, model, or fuel type level, could provide more detailed insights. A refined assessment of the demographics of various material grades, shapes, or alloying elements may provide relevant insights on the dynamics of materials with specific properties and different recycling potentials. Such information may support investment in scrap handling techniques and increased value for the upcoming recycled material. Another potential improvement would be a breakdown of each cohort by new additions and removals from the previous period. This would provide enhanced information on stock dynamics and enable the simultaneous representation of material flows and stocks, for example with Sankey diagrams and demographic pyramids. Such information would distinguish new materials used for maintenance of existing stock (e.g., a new car bought to replace an old one) from absolute expansion or contraction.

The use of stock demographics has some limitations. This approach requires comprehensive data availability on material composition and service delivery, and further insights depend on further data refinement on product categories, materials, grades, shapes, and services. Such data is required for each age cohort and over time. The need for service data is also an important limitation, because service metrics depend on each product and its function. Some products are used to provide a single function, but others may provide a vast set of services, each of them requiring a different unit. Also, some services may not be directly quantified. These cases would require the definition of meaningful proxies or indexes of aggregated service metrics.

The evolution of the composition of stocks of a product may also be useful to examine the dynamics of early adoption or phasing-out stages. However, stock demographics is only capable of providing insights for established products, so that purchasing and replacement dynamics can be anticipated. For these cases, stock demographics can provide a representation of the evolution of material stocks, but more comprehensive information is required to anticipate stocks' dynamics.

\section{ASSOCIATED CONTENT}

\section{S Supporting Information}

The Supporting Information is available free of charge on the ACS Publications website at DOI: 10.1021/acs.est.5b05012.

Material composition and service delivery estimated for cars in Great Britain, and yearly stock demographics graphs obtained from 2002 to 2012 (PDF)

\section{AUTHOR INFORMATION}

\section{Corresponding Author}

*Phone: +44 (0) 1223 764775; e-mail: ag806@cam.ac.uk.

\section{Notes}

The authors declare no competing financial interest.

\section{ACKNOWLEDGMENTS}

This work was supported by EPSRC, grant reference EP/ N02351X/1. The authors also thank Dr. Alexandra Skelton for her valuable comments.

\section{REFERENCES}

(1) Pauliuk, S.; Müller, D. B. The role of in-use stocks in the social metabolism and in climate change mitigation. Global Environ. Change 2014, 24 (1), 132-142.

(2) Allwood, J. M.; Cullen, J. M.; Carruth, M. A.; Cooper, D. R.; McBrien, M.; Milford, R. L.; Moyniham, M. C.; Patel, A. C. H. Sustainable Materials with Both Eyes Open; UIT Cambridge: Cambridge, UK, 2012.

(3) Fischedick, M.; Roy, J.; Abdel-Aziz, A.; Acquaye, A.; Allwood, J. M.; Ceron, J.-P.; Geng, Y.; Kheshgi, H.; Lanza, A.; Perczyk, D.; Price, L.; Santalla, E.; Sheinbaum, C.; Tanaka, K., Industry. In Climate Change 2014: Mitigation of Climate Change. Contribution of Working Group III to the Fifth Assessment Report of the Intergovernmental Panel on Climate Change, Edenhofer, O.; Pichs-Madruga, R.; Sokona, Y.; Farahani, E.; Kander, S.; Seyboth, K.; Adler, A.; Baum, I.; Brunner, S.; Eickemeier, P.; Kriemann, B.; Savolainen, J.; Schlömer, S.; von Stechow, C.; Zwickel, T.; Minx, J. C., Eds.; Cambridge University Press: Cambridge, U.K., 2014.

(4) Birat, J.-P.; Daigo, I.; Matsuno, Y. Methods to Evaluate Environmental Aspects of Materials. In Treatise on Process Metallurgy; Seetharaman, S., Ed.; Elsevier: Boston, 2014; Chapter 4.3, pp 14591505.

(5) Leal-Ayala, D.; Allwood, J. M.; Bloodworth, A.; Cilliers, J.; Moore, K. HOSANA Whole Systems Analysis; University of Cambridge, Imperial College, British Geological Survey, Camborne School of Mines: Cambridge, U.K., 2014.

(6) Huang, C.-L.; Vause, J.; Ma, H.-W.; Yu, C.-P. Using material/ substance flow analysis to support sustainable development assessment: A literature review and outlook. Resources, Conservation and Recycling 2012, 68, 104-116.

(7) Fischer-Kowalski, M.; Krausmann, F.; Giljum, S.; Lutter, S.; Mayer, A.; Bringezu, S.; Moriguchi, Y.; Schütz, H.; Schandl, H.; Weisz, $\mathrm{H}$. Methodology and Indicators of Economy-wide Material Flow Accounting. J. Ind. Ecol. 2011, 15 (6), 855-876.

(8) Chen, W. Q.; Graedel, T. E. Improved alternatives for estimating in-use material stocks. Environ. Sci. Technol. 2015, 49 (5), 3048-3055.

(9) Müller, E.; Hilty, L. M.; Widmer, R.; Schluep, M.; Faulstich, M. Modeling metal stocks and flows: A review of dynamic material flow analysis methods. Environ. Sci. Technol. 2014, 48 (4), 2102-2113.

(10) Tanikawa, H.; Fishman, T.; Okuoka, K.; Sugimoto, K. The weight of society over time and space: A comprehensive account of the construction material stock of Japan, 1945-2010. J. Ind. Ecol. 2015, 19 (5), 778-791.

(11) Fishman, T.; Schandl, H.; Tanikawa, H. The socio-economic drivers of material stock accumulation in Japan's prefectures. Ecological Economics 2015, 113, 76-84.

(12) Wang, T.; Müller, D. B.; Hashimoto, S. The ferrous find: Counting iron and steel stocks in China's economy. J. Ind. Ecol. 2015, 19 (5), 877-889.

(13) Müller, D. B.; Bader, H. P.; Baccini, P. Long-term coordination of timber production and consumption using a dynamic material and energy flow analysis. J. Ind. Ecol. 2004, 8 (3), 65-87.

(14) Müller, D. B. Stock dynamics for forecasting material flowsCase study for housing in The Netherlands. Ecological Economics 2006, 59 (1), $142-156$.

(15) Sandberg, N. H.; Brattebø, H. Analysis of energy and carbon flows in the future Norwegian dwelling stock. Building Research and Information 2012, 40 (2), 123-139.

(16) Sandberg, N. H.; Sartori, I.; Brattebø, H. Sensitivity analysis in long-term dynamic building stock modeling - Exploring the importance of uncertainty of input parameters in Norwegian segmented dwelling stock model. Energy and Buildings 2014, 85, $136-144$. 
(17) Hu, M.; Pauliuk, S.; Wang, T.; Huppes, G.; van der Voet, E.; Müller, D. B. Iron and steel in Chinese residential buildings: A dynamic analysis. Resources, Conservation and Recycling 2010, 54 (9), 591-600.

(18) Busch, J.; Steinberger, J. K.; Dawson, D. A.; Purnell, P.; Roelich, K. Managing critical materials with a technology-specific stocks and flows model. Environ. Sci. Technol. 2014, 48 (2), 1298-1305.

(19) Pauliuk, S.; Wang, T.; Müller, D. B. Moving toward the circular economy: The role of stocks in the Chinese steel cycle. Environ. Sci. Technol. 2012, 46 (1), 148-154.

(20) Modaresi, R.; Pauliuk, S.; Løvik, A. N.; Müller, D. B. Global carbon benefits of material substitution in passenger cars until 2050 and the impact on the steel and aluminum industries. Environ. Sci. Technol. 2014, 48 (18), 10776-10784.

(21) Løvik, A. N.; Modaresi, R.; Müller, D. B. Long-term strategies for increased recycling of automotive aluminum and its alloying elements. Environ. Sci. Technol. 2014, 48 (8), 4257-4265.

(22) Oguchi, M.; Fuse, M. Regional and longitudinal estimation of product lifespan distribution: A case study for automobiles and a simplified estimation method. Environ. Sci. Technol. 2015, 49 (3), $1738-1743$.

(23) EPA MOVES (Motor Vehicle Emission Simulator). http:// www3.epa.gov/otaq/models/moves/index.htm.

(24) ARB EMFAC models. http://www.arb.ca.gov/msei/modeling. htm.

(25) Pauliuk, S.; Hertwich, E. Prospective Models of Society's Future Metabolism: What Industrial Ecology Has to Contribute. In Taking Stock of Industrial Ecology; Clift, R.; Druckman, A., Eds.; Springer: Boston, MA, 2016.

(26) Keyfitz, N. Applied Mathematical Demography; John Wiley \& Sons: New York, 1977.

(27) Swanson, D. A.; Burch, T. K.; Tedrow, L. M. What is applied demography? Population Research and Policy Review 1996, 15 (5/6), 403-418.

(28) Swanson, D. A.; Pol, L. G. Contemporary developments in applied demography within the United States. Sociological Practice 2004, 6 (2), 26-56.

(29) Murdock, S. H.; Swanson, D. A. Applied Demography in the 21st Century; Springer: Boston, MA, 2008.

(30) Thompson, W. S.; Lewis, D. T. Population problems, 5th ed.; McGraw-Hill: New York, 1965.

(31) Department for Transport Licensed cars by years since first registration, Great Britain, annually: 1994 to 2014. https://www.gov. uk/government/statistical-data-sets/veh02-licensed-cars (accessed March 16, 2015).

(32) CAR. Automotive Technology: Greener Products, Changing Skills. Lightweight Materials \& Forming Report; Center for Automotive Research: Ann Arbor, MI, 2011.

(33) Keoleian, G. A.; Sullivan, J. L. Materials challenges and opportunities for enhancing the sustainability of automobiles. MRS Bull. 2012, 37 (4), 365-372.

(34) ICCT. European Vehicle Market Statistics: Pocketbook 2014; International Council on Clean Transportation Europe: Berlin, Germany, 2014.

(35) ICCT. European Vehicle Market Statistics. http:// eupocketbook.theicct.org (accessed July 22, 2015).

(36) Ajanovic, A.; Schipper, L.; Haas, R. The impact of more efficient but larger new passenger cars on energy consumption in EU-15 countries. Energy 2012, 48 (1), 346-355.

(37) Schäfer, A.; Heywood, J. B.; Jacoby, H. D.; Waitz, I. A. Transportation in a Climate-Constrained World; MIT Press: Cambridge, MA, 2009.

(38) Department for Transport, National Travel Survey, 2002-2012 [computer file], 8th ed.; UK Data Archive: Colchester, Essex, UK, 2014.

(39) European Commission. Reducing $\mathrm{CO}_{2}$ emissions from passenger cars. http://ec.europa.eu/clima/policies/transport/ vehicles/cars/index_en.htm (accessed October 9, 2015).

(40) Serrenho, A. C.; Mourão, Z. S.; Norman, J. B.; Cullen, J. M.; Allwood, J. M. The influence of UK emissions reduction targets on the emissions of the global steel industry. Resources, Conservation and Recycling 2016, 107, 174-184.

(41) Gutowski, T. G.; Allwood, J. M.; Herrmann, C.; Sahni, S. A global assessment of manufacturing: Economic development, energy use, carbon emissions, and the potential for energy efficiency and materials recycling. Annual Review of Environment and Resources 2013, $38,81-106$. 